\title{
A pilot study of virtual reality as an alternative to pharmacological sedation during colonoscopy
}

\section{두)(웅}

\author{
Authors \\ Institutions \\ 1 Gastroenterology Division, Department of Medicine, \\ Massachusetts General Hospital, Harvard Medical \\ School, Boston, Massachusetts, United States \\ 2 Rendever, Incorporated, Somerville, Massachusetts, \\ United States
}

Madeline Friedman ${ }^{1}$, Kyle Rand ${ }^{2}$, Tobias Patel ${ }^{2}$, Francis Colizzo ${ }^{1}$, Peter Carolan ${ }^{1}$, Peter Kelsey ${ }^{1}$, Daniel C. Chung ${ }^{1}$

submitted 21.7.2020

accepted after revision $\quad 5.10 .2020$

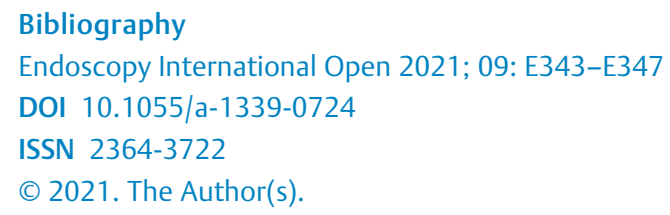

Chung.Daniel@mgh.harvard.edu

\begin{abstract}
Background and study aims Conscious sedation is routinely administered for colonoscopy but is associated with risks and inconveniences. We sought to determine whether virtual reality (VR) may be a feasible alternative.
\end{abstract}

Patients and methods Twenty-seven individuals scheduled for screening/surveillance colonoscopy participated. The VR device was activated throughout the colonoscopy, but subjects could opt out and request standard medications. Questionnaires were administered, and variables were assessed on a scale of 1 to 10 .

Results Cecal intubation was achieved in all cases without adverse events (AEs). Study colonoscopies were completed without pharmacological rescue in 26 of 27 patients (96.3\%) and procedure times were comparable to baseline. Subjects reported minimal pain, high satisfaction, and willingness to use VR for future colonoscopies to avoid narcotics and resume normal activities including driving.

Conclusion Replacing pharmacological sedation with VR did not impact colonoscopy completion rates, procedure time, or AEs. Satisfaction was high and only one subject (3.7\%) chose to suspend VR. VR can be an effective alternative for patients undergoing colonoscopy who prefer to avoid narcotics.

\section{Introduction}

Sedative and narcotic medications used during colonoscopy can cause nausea/vomiting, absence from work, impaired cognitive function and need for an escort home. These factors are often cited as reasons patients delay or avoid colonoscopy [1]. Unsedated colonoscopy is not widely accepted [2] and inferior in quality to sedated exams [3]. This highlights the need for non-pharmacological anxiolysis and analgesia during colonoscopy.

In previous studies, virtual reality (VR) significantly reduced pain perception in medical settings including burn wound care $(P<0.0001)$ [4] and dental procedures $(P=0.000)$ [5]. We sought to determine whether VR may be an acceptable alternative to pharmacological sedation during colonoscopy.

\section{Patients and methods}

\section{Patient selection}

Over a 9-month period, all individuals scheduled for screening/ surveillance colonoscopy who had previously undergone $\geq 1$ colonoscopy under conscious sedation and were patients of any of four endoscopists at our institution were invited to participate. First-time colonoscopy patients and those who had prior colonoscopies under anesthesia or without sedation were excluded to specifically compare VR to conscious sedation. Patients with 
contraindications to conscious sedation were excluded so that all subjects had the option of pharmacological rescue.

\section{VR delivery}

Subjects were oriented to the VR device prior to their procedure. We used the Samsung (Ridgefield Park, New Jersey, United States) Gear VR Oculus headset fitted with a Samsung Galaxy S7 phone. Subjects could opt out and request standard pain medications at any time before or during their procedure.

In addition to study consent, all subjects signed a standard consent for colonoscopy with medications. Virtual experiences were initiated just prior to colonoscope insertion and continuously delivered throughout the procedure. Subjects were repositioned as needed at the discretion of the performing endoscopist. In these situations, the care team communicated over the audio component of the VR rather than interrupt. Patients experienced multiple 1- to 7-minute audiovisual experiences featuring nature and animal scenes. All were passive VR that did not require the viewer to move or direct travel through the virtual environment and were considered by the investigators to be relaxing and engaging.

\section{Statistical analysis}

Data were compared with the Mann-Whitney and Fisher tests. Relationship strength between continuous data sets was assessed using the Pearson $r$ correlation. Variables are presented as mean \pm standard deviation. The study was IRB-approved and registered with ClinicalTrials.gov (NCT04349150).

\section{Results}

\section{Cohort characteristics}

Twenty-seven individuals ( 13 male, mean age $63.9 \pm 8.4$ years) initiated their colonoscopy with the VR device ( $>$ Table 1 ). The cecum was intubated in all cases. Eleven subjects (40.7\%) had a history of abdominal or pelvic surgery, and one had a tortuous colon noted on prior colonoscopy. No other conditions that might impact the exam were noted. 22 (81.5\%) had one or more prior colonoscopies performed by the same endoscopist who did the study exam. Five $(18.5 \%)$ had their prior procedures performed by a different endoscopist at our institution. Mean drug doses administered during prior colonoscopies were $3.7 \pm 1.2 \mathrm{mg}$ midazolam $/ 70.6 \pm 21.2 \mathrm{mg}$ meperidine and $4.2 \pm 1.1 \mathrm{mg}$ midazolam/103.9 $\pm 44.3 \mu \mathrm{g}$ fentanyl.

\section{Colonoscopies completed with VR and no pharmacological rescue}

Of the participants, $96.3 \%$ (26/27) completed their colonoscopy without requesting or receiving any sedative or narcotic medication. These 26 subjects rated their pre-procedure anxiety at a mean of $3.8 \pm 2.2 / 10$, procedural pain at $3.6 \pm 1.6 / 10$, and discomfort at $4.0 \pm 1.4 / 10$ ( $1=$ no anxiety/pain/discomfort, $10=$ extreme anxiety/pain/discomfort). Subjects compared their feelings to those experienced at their prior colonoscopy. The results are described in $>$ Table 2 . Overall, pre-procedure anxiety was weakly correlated with pain $(r=0.33)$ and discomfort $(r=0.44)$.
- Table 1 Baseline characteristics of study cohort

\begin{tabular}{|l|l|}
\hline Number & 27 \\
\hline Sex (M:F) & $13: 14$ \\
\hline Mean age, $y \pm$ SD & $63.9 \pm 8.4$ \\
\hline Mean BMI, kg/m² \pm SD & $26.2 \pm 3.8$ \\
\hline $\begin{array}{l}\text { No. of prior colonoscopies - } \\
\mathrm{n}(\%)\end{array}$ & $\begin{array}{l}1 \text { colonoscopy }-8(29.6) \\
2 \text { colonoscopies }-10(37.0) \\
\geq 3 \text { colonoscopies }-9(33.3)\end{array}$ \\
\hline $\begin{array}{l}\text { Medical history potentially } \\
\text { impacting exam difficulty - } \\
\text { n (\%) }\end{array}$ & $\begin{array}{l}\text { Abdominal/pelvic surgery }-11(40.7) \\
\text { Tortuous colon }-1(3.7)\end{array}$ \\
\hline $\begin{array}{l}\text { At least } 1 \text { prior colonoscopy }-15(55.6) \\
\text { performed by study endos- } \\
\text { copist }\end{array}$ & $\begin{array}{l}\text { Yes }-22(81.5) \\
\text { No }-5(18.5)\end{array}$ \\
\hline $\begin{array}{l}\text { Mean medication doses } \\
\text { (meperidine) in prior colo- } \\
\text { noscopies, } \pm \text { SD }\end{array}$ & $\begin{array}{l}3.7 \pm 1.2 \text { mg midazolam } \\
70.6 \pm 21.2 \text { mg meperidine }\end{array}$ \\
\hline $\begin{array}{l}\text { Mean medication doses } \\
\text { (fentanyl) in prior colonos- } \\
\text { copies, } \pm \text { SD }\end{array}$ & $\begin{array}{l}4.2 \pm 1.1 \text { mg midazolam } \\
103.9 \pm 44.3 \mu g \text { fentanyl }\end{array}$ \\
\hline \begin{tabular}{l} 
SD, standard deviation; BMI, body mass index \\
\hline
\end{tabular} & \\
\hline
\end{tabular}

Six of 26 patients (23.1\%) considered asking for medication at some time during their procedure. All refrained because any pain was not severe or quickly subsided, the endoscopist indicated the cramping was almost over, and they wanted to finish the colonoscopy without medications.

The mean duration of the 26 colonoscopies during which no medication was used was $22.6 \pm 8.9$ minutes (scope in to scope out) ( $\triangleright$ Table 2 ). This was not significantly different from the baseline average procedure time of the four endoscopists (21.6 minutes, $P=0.23$ ). Thirteen individuals ( $50.0 \%$ ) had diverticulosis and a mean of $2.1 \pm 1.8$ polyps were removed in $11 \mathrm{pa}$ tients $(42.3 \%)$. Polyps were a mean of $4.9 \pm 3.8 \mathrm{~mm}$ and included sessile serrated polyps/adenomas, tubular adenomas, hyperplastic polyps, and serrated adenomas. The endoscopist noted difficulties during three procedures (11.5\%), which included performing difficult maneuvers to retrieve polyps, frequent repositioning, and administering abdominal counterpressure. One of these individuals had a history of appendectomy and cholecystectomy. All had diverticulosis, though diverticulosis was not significantly associated with difficulties $(P=0.22)$. There was no other history that might impact the difficulty of the procedure. The mean age of these three subjects was 75.0 years, which was significantly different from the 24 with no difficulties (62.5 years, $P=0.02$ ).

\section{Patient motivations for choosing VR}

Motivations for using VR instead of pharmacological sedation were assessed on a scale of 1 to 10 ( 1 = "this outcome did not motivate me to try VR," 10 = "this outcome strongly motivated me to try VR") ( $\triangleright$ Fig. 1). Among the 26 patients who did not request medication, being able to drive and perform normal ac- 
Table 2 Patient experience and study data on colonoscopy

\begin{tabular}{|c|c|c|}
\hline Patient experience with virtual reality & $\begin{array}{l}\text { No medication requested during } \\
\text { colonoscopy }(n=26)\end{array}$ & $\begin{array}{l}\text { Medication requested during } \\
\text { colonoscopy }(n=1)\end{array}$ \\
\hline Pre-procedure anxiety; mean $\pm \mathrm{SD}^{1}$ & $3.8 \pm 2.2$ & 3 \\
\hline Anxiety compared to first colonoscopy - n (\%) & $\begin{array}{l}\text { Less anxiety - } 11(42.3) \\
\text { Similar anxiety }-8(30.8) \\
\text { More anxiety - } 3(11.5) \\
\text { Anxious about study, not about proce- } \\
\text { dure - } 3(11.5) \\
\text { Do not remember - } 1(3.8)\end{array}$ & More anxiety - 1 (100) \\
\hline Procedural pain; mean \pm SD ${ }^{1}$ & $3.6 \pm 1.6$ & 2 \\
\hline Pain compared to prior colonoscopies - n (\%) & $\begin{array}{l}\text { Less pain - } 1(3.8) \\
\text { Similar pain }-11(42.3) \\
\text { More pain }-11(42.3) \\
\text { No response }-3(11.5)\end{array}$ & More pain - $1(100)$ \\
\hline Procedural discomfort; mean $\pm \mathrm{SD}^{1}$ & $4.0 \pm 1.4$ & 4 \\
\hline Discomfort compared to prior colonoscopies - n (\%) & $\begin{array}{l}\text { Less discomfort - } 1(3.8) \\
\text { Similar discomfort - } 11(42.3) \\
\text { More discomfort - } 13(50.0) \\
\text { No response }-1(3.8)\end{array}$ & More discomfort - 1 (100) \\
\hline $\begin{array}{l}\text { How satisfied are you with your overall experience? } \\
\text { Mean } \pm S D^{2}\end{array}$ & $7.3 \pm 2.5$ & 3 \\
\hline $\begin{array}{l}\text { Would you choose VR instead of pain medication for } \\
\text { colonoscopy again? - n (\%) }\end{array}$ & $\begin{array}{l}\text { Yes }-18(69.2) \\
\text { Maybe }-7(26.9) \\
\text { No }-1(3.8)\end{array}$ & No $-1(100.0)$ \\
\hline $\begin{array}{l}\text { How likely are you to recommend VR during colonoscopy } \\
\text { to a friend or family member? Mean } \pm \text { SD, scale } 1-10^{3}\end{array}$ & $7.4 \pm 2.4$ & 1 \\
\hline \multicolumn{3}{|l|}{ Colonoscopy characteristics } \\
\hline Mean duration of colonoscopy, minutes \pm SD & $22.6 \pm 8.9$ & 19.0 \\
\hline Diverticula noted, n (\%) & $13(50.0)$ & $1(100.0)$ \\
\hline Polyps removed, n (\%) & $11(42.3)$ & $1(100.0)$ \\
\hline Mean number of polyps per subject with polyps \pm SD & $2.1 \pm 1.8$ & 1 \\
\hline Mean polyp size, $\mathrm{mm} \pm \mathrm{SD}$ & $4.9 \pm 3.8$ & 1.0 \\
\hline \multicolumn{3}{|c|}{$\begin{array}{l}\text { SD, standard deviation; VR, virtual reality } \\
{ }^{1} \text { Scale of } 1-10(1=\text { no anxiety/pain/discomfort, } 10=\text { extreme anxiety/pain/discomfort). } \\
{ }^{2} \text { Scale of } 1-10(1=\text { not satisfied, } 10=\text { extremely satisfied }) \\
{ }^{3} \text { Scale of } 1-10(1=\text { not likely, } 10=\text { extremely likely })\end{array}$} \\
\hline
\end{tabular}

tivities following the procedure was the strongest motivator for choosing VR (mean score $7.5 \pm 2.5 / 10$ ), followed by not wanting to receive narcotics $(7.4 \pm 3.0 / 10)$. Moderate motivators included not thinking the procedure is uncomfortable $(6.8 \pm 2.4$ / $10)$ and not needing an escort for pick-up $(5.8 \pm 3.5 / 10)$. In addition to these options given in the questionnaire, one subject added "no nausea" as a 10/10 motivator, and another reported "less medication in my body" as a 9/10 motivator.

\section{Patient satisfaction with VR}

Subjects who completed their colonoscopy without medication rated their satisfaction with their colonoscopy/VR experience at a mean of $7.3 \pm 2.5 / 10$ ( $\triangleright$ Table 2). Satisfaction was weakly associated with pain $(r=-0.49)$ and discomfort $(r=-0.46)$ but did not correlate with the strength of a patient's motivation to use VR $(r=0.13)$.

When asked if they would choose VR instead of pain medication for future colonoscopies, 18 of 26 subjects who did not request medication (69.2\%) said "yes," and seven $(26.9 \%)$ said "maybe," Only one subject $(3.8 \%)$ indicated that she would not choose VR for future colonoscopies. The subjects' likelihood of recommending VR during colonoscopy to a friend/family member was $7.4 \pm 2.4 / 10 \quad(1=$ not likely, $10=$ very likely $)$ ( Table 2). 


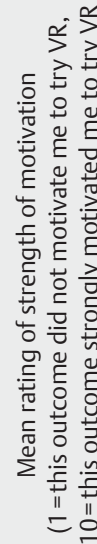

1

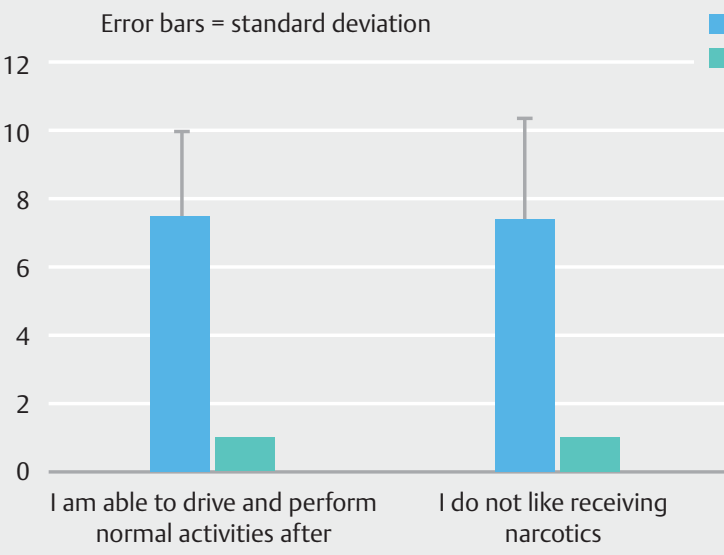

Individuals who completed colonoscopy using VR only $(\mathrm{n}=26)$
Individual who requested pharmacological sedation after initiating colonoscopy with VR $(n=1)$

- Fig. 1 Mean scores for motivations for choosing virtual reality instead of pharmacological sedation during colonoscopy. Blue indicates individuals who completed colonoscopy using virtual reality and no pharmacological rescue $(n=26)$. Green indicates the individual who requested pharmacological rescue after initiating colonoscopy with virtual reality $(n=1)$. Y-axis: Score. $1=$ "This outcome did not motivate me to try virtual reality." 10 = "This outcome strongly motivated me to try virtual reality." Error bars indicate standard deviation.

\section{Endoscopist experience with VR}

Endoscopists rated their overall experience with VR subjects at a mean of $8.6 \pm 1.8 / 10$ ( 1 = poor, $10=$ excellent). This number increased to $9.0 \pm 0.8 / 10$ for 22 procedures during which no difficulties were noted and dropped to $5.0 \pm 3.0 / 10$ for the three procedures with difficulties. All endoscopists reported that they would be comfortable incorporating VR as a pain-management strategy into their colonoscopy practice ( $N=25$ : 19 -yes, I would be comfortable; 6 -yes, but I would use it as an adjunct therapy).

\section{Discussion}

In this pilot study of VR as an alternative to pharmacological sedation in routine colonoscopy, $96.3 \%$ of subjects completed their colonoscopy using VR without any sedative or narcotic medications. Patient-reported pain was minimal, satisfaction was high, and the majority of patients indicated they would use VR instead of conscious sedation for future colonoscopies. Effective pain management is crucial for colonoscopy patients because high levels of pain decrease colonoscopy completion rates and willingness to return for repeat colonoscopies [6, 7]. Our findings corroborate other studies that point to VR as an effective anxiolytic and analgesic that does not compromise patient care or satisfaction $[4,5]$.

Although we have shown that VR may be used as a substitute for medication in motivated individuals, in $24 \%$ of cases, endoscopists reported that they would prefer to use VR along with medications. This strategy may enhance the effects of lower doses of narcotics and anxiolytics. Such adjunctive use of VR during colonoscopy has been shown to be feasible [8], and future studies should investigate whether VR decreases the medication dose required. Opioid shortages have occurred due to supply chain disturbances. These situations necessitate the optimization of non-pharmacological therapies and prioritizing indications for opioid use [9]. Screening colonoscopies would be considered low priority, and VR could play an important role in mitigating colonoscopy-associated pain and anxiety during these times. VR may even be a safer alternative than an unfamiliar analgesic, as introducing unfamiliar drugs increases the risk of medical error [10].

A strategy that incorporates VR into a colonoscopy workflow is also likely to offer systemic cost savings. This can be attributed to decreased medication costs, reduced time and resources required in the recovery room, and reduced costs associated with a day of missed work for both the patient and escort. As need for an escort and concerns about sedation are common barriers to obtaining colonoscopy [1], a non-pharmacological pain-management strategy could make colonoscopy more accessible and ultimately, more utilized.

\section{Conclusion}

In conclusion, our findings indicate that VR is a feasible alternative to conscious sedation during colonoscopy for patients motivated to avoid sedatives and narcotics.

\section{Acknowledgments}

The authors report non-financial support from Rendever, Inc. for the conduct of this study.

\section{Competing interests}

Mr. Rand is an owner of Rendever, Inc. Mr. Patel is an employee of Rendever, Inc. 


\section{References}

[1] Jetelina KK, Yudkin JS, Miller S et al. Patient-reported barriers to completing a diagnostic colonoscopy following abnormal fecal immunochemical test among uninsured patients. J Gen Intern Med 2019; 34: $1730-1736$

[2] Early DS, Saifuddin T, Johnson JC et al. Patient attitudes toward undergoing colonoscopy without sedation. Am J Gastroenterol 1999; 94: 1862-1865

[3] Radaelli F, Meucci G, Sgroi G et al. Technical performance of colonoscopy: the key role of sedation/analgesia and other quality indicators. Am J Gastroenterol 2008; 103: 1122-1130

[4] Luo H, Cao C, Zhong J et al. Adjunctive virtual reality for procedural pain management of burn patients during dressing change or physical therapy: A systematic review and meta-analysis of randomized controlled trials. Wound Repair Regen Off Publ Wound Heal Soc Eur Tissue Repair Soc 2019; 27: 90-101
[5] Alshatrat SM, Alotaibi R, Sirois M et al. The use of immersive virtual reality for pain control during periodontal scaling and root planing procedures in dental hygiene clinic. Int J Dent Hyg 2019; 17: 71-76

[6] Church JM. Complete colonoscopy: how often? And if not, why not? Am J Gastroenterol 1994; 89: 556-560

[7] Sewitch M], Gong S, Dube C et al. A literature review of quality in lower gastrointestinal endoscopy from the patient perspective. Can J Gastroenterol J Can Gastroenterol 2011; 25: 681-685

[8] Veldhuijzen G, Klaassen NJM, Van Wezel RJA et al. Virtual reality distraction for patients to relieve pain and discomfort during colonoscopy. Endosc Int Open 2020; 8: E959-E966

[9] Clark SL, Levasseur-Franklin K, Pajoumand M et al. Collaborative management strategies for drug shortages in neurocritical care. Neurocrit Care 2020; 32: 226-237

[10] A Shortage of Everything Except Errors: Harm Associated With Drug Shortages. Inst Safe Medicat Pract; https://www.ismp.org/resources/ shortage-everything-except-errors-harm-associated-drug-shortages 